\title{
ESTIMATING THE DEGREE OF REGION'S VULNERABILITY IN CASE OF NATURAL DISASTERS
}

\author{
Ghiță BÂRSAN*, Anca DINICU*, Vasile NĂSTĂSESCU**, Romana OANCEA* \\ *"Nicolae Bălcescu" Land Forces Academy, Sibiu, Romania \\ **Military Technical Academy, Bucharest, Romania \\ gbarsan@armyacademy.ro, anca_dinicu@yahoo.com,oancea.romana@gmail.com
}

\begin{abstract}
Estimating the degree of vulnerability of a region implies both the identification of the dependencies as well as of the interdependencies. The dependencies refer to a set of physical, social, economic, environmental and political-military conditions and processes and the interdependencies have in view physical, cyber, geographical and logical aspects that may indirectly affect the daily rhythm of the population, the economy or even the national security. The present paper aims at estimating the degree of vulnerability by constructing a model that would determine the index of vulnerability associated to a given area, an index that is directly dependent on demographic, economic, governmental factors, on the interdependence with other sectors and also on the history of the events that occurred in the area in the recent years.
\end{abstract}

\section{Keywords: critical infrastructure, vulnerability, interdependency}

\section{Introduction}

The ability to measure vulnerability is essential for reducing risks to disasters, but it also requires accurate identification and understanding of the threats that directly influence risk. There must be a clear distinction between damage, impact and vulnerability assessment, and indicators and benchmarks are key elements in measuring vulnerability and adaptive capacity of the system [1].

To reduce vulnerabilities, various models can be built, in order to model and quantify risk and allocate resources optimally. Therefore, the strategy requires identifying and providing protection for various critical infrastructures which may directly or indirectly influence the health and safety of the population, the economic and governmental situation or citizens' trust. Identifying and prioritizing the most critical components of critical infrastructure remains a topical issue [2] and predicting consequences, which vary according to the intensity of the disaster or the sector in which it occurs, is a challenge. Generally speaking, an infrastructure is vulnerable mainly because it can contain many components and then dependencies or interdependencies are complex and varied.

Professional literature is not consistent when it comes to classifying interdependencies in the field, or the number of categories. However, the classification mostly referred to is the one developed by Rinaldi, Peerenboom and Kelly that envisages four classes of interdependencies: [3]

- Physical - the end product of an infrastructure constitutes raw material for another infrastructure and the temporary incapacity can produce a chain of negative effects. Compromising crops from natural disasters affects food supply to the population. 
- Cyber - dependence on the transfer of information;

- Geographical - negative effects occur because of proximity to an affected component. For example, bridge damage due to flooding can disrupt electricity in the region because of power lines in the vicinity of the flooded area.

- Logical - interdependence due to an event that has a direct impact on social factors: lack of confidence or public fear or political factors.

On grounds of complexity, a synergy between history, theory and technical instruments is required. In general, vulnerability is directly dependent on a set of conditions and processes resulting from physical, social, economic, environmental and political-military factors. In assessing vulnerabilities, there are tangible losses that can be measured, but also intangible that cannot be measured or quantified easily. For example, it is very difficult to estimate the psychological consequences following a disaster or the social and cultural disruption. Tangible losses can be described, measured or quantified by various methods.

Interdependence is not a strict feature of the critical infrastructure domain. It is actually one of the pillars on which the world we live in is built, in this context of globalization.

Reported to the topic analyzed in this paper, interdependence refers to the complex network of relationships in which the sectors of critical infrastructure are both due to geographical proximity and because of communication and information technologies that make them function as a system of systems.

The interdependence of critical infrastructure is an obvious reality, as demonstrated by situations that have managed to create problems to national security, by exploiting specific vulnerabilities. In this regard, we can mention the following examples showing that what happens to the infrastructure may directly or indirectly affect other infrastructures, can have an impact on large geographical regions and can send shocks to the national and global economy, as well as to the daily rhythm in which people live their lives:

- November $9^{\text {th }}, 1965$ - the largest blackout in US history; consequences: 30 million people in seven states in northeastern America and part of Canada were left without electricity, paralyzing public transport and endangering the activity in various fields, some of them strategic (oil and gas production);

- failure of the telecommunications satellite Galaxy 4, in 1998; consequences: disrupting telecommunications in the United States, almost total paralysis of the paging service, banking and financial services business disruption or those of medical emergency;

- March 31 $1^{\text {st }}, 2015$ - the largest power failure of the last 15 years in Turkey (mainly Ankara and Istanbul); consequences: air traffic disruption, paralyzing shopping centers and urban public transport.

Therefore, what happens to the infrastructure may directly or indirectly affect other infrastructures, can have an impact on large geographical regions and can send shocks to the national and global economy.

\section{Determination of the degree of vulnerability in the event of natural disasters}

To determine the degree of vulnerability in the event of natural disasters, we started from Disaster Risk Index developed by the United Nations Development Programme and defined vulnerability index based on various indicators: [4], [5]

$V_{\text {index }}=c * V_{\text {demography }} * V_{\text {ecomonic }} * V_{\text {policy }} * V_{\text {interdependency }}$

where:

- $c$ - is a constant representing the number of events of the same type produced in the area

- $V_{\text {demography }}$ - demographic vulnerability dependent on demographic factors 
- $V_{\text {economic }}$ - economic vulnerability, as economic factors and the type of economic activities in the region

- $V_{\text {policy }}$-governmental vulnerability as a measure of government policies and the existence of legislation for risk management

- $V_{\text {interdependency }}$ - vulnerabilities due to dependencies and interdependencies with other sectors

- $V_{\text {index }}{ }^{-}$vulnerability index. A low value indicates a low vulnerability.

From a demographic perspective, an important factor concerns the very young or aged population, because these groups need help in case of natural disasters requiring evacuation. At the same time, a higher population may slow response time due to limitations in the transport network and may involve more specialized forces for help or escape which requires a highly developed disaster management. In general, responsiveness to crises is better for the urban population than in rural areas and procedures of decision - making in disaster management is crucial for successful pre and post-disaster activity [5]. Another aspect relates to education. A large percentage of illiterate population increases the degree of vulnerability due to the inability to understand the scale of the disaster or to accept the emergency measures required or maybe to understand warning messages.

The economic level of the region directly affects the ability of reconstruction or the return to a state as close to normality on the one hand, on the other hand it directly influences the protection of the population by the existence of solid houses offering better protection in the event of disaster, the developed transport networks or major buildings that could be used for evacuation or relocation. [6] Vulnerability is directly linked to poverty. A poor society has few resources and opportunities to significantly reduce vulnerability [7]. Studies have shown that the poorest countries are the most prone to natural disasters. [8] Moreover, the type of economic activity directly influences the degree of vulnerability. A predominantly agricultural activity will be affected by both floods and drought. Destruction of agricultural crops has long-term repercussions on the economy and in the short term to ensure the food needs of the population in the area.

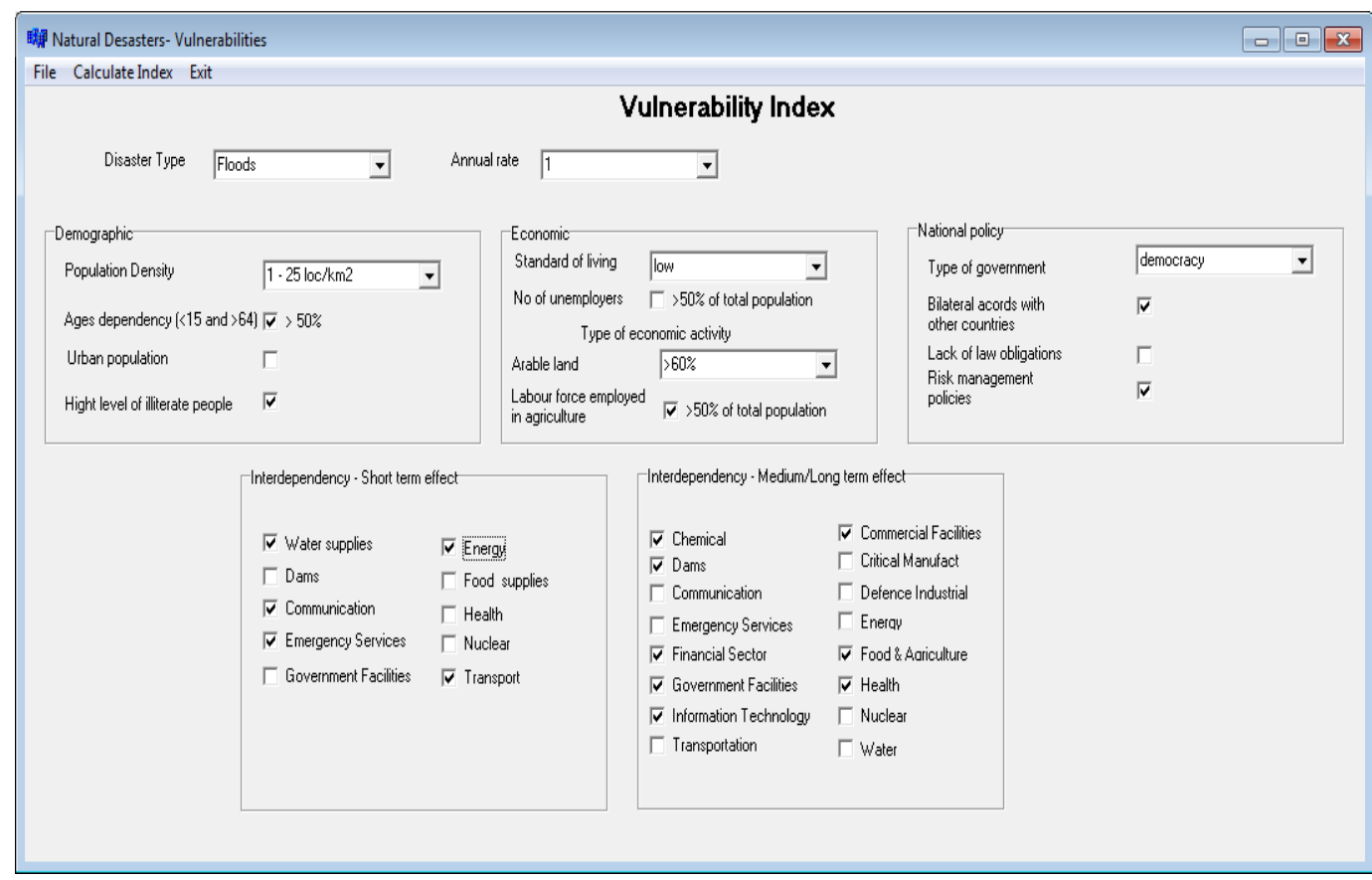

Figure 1 Indicators for Determination of Vulnerability Index 
Government defines national policies that directly or indirectly affects and influences the level of vulnerability. A democratic government can have international agreements with other states, and in case of a major disaster aid may come from external partners. A government, other than democratic, may restrict access to information and communication means such as internet access or limiting coverage of mobile telephony can have negative effects on the population and the economy. In case of extreme temperatures that may affect gas supplies or power at the national level, alternative sources of energy production may be used, if any, or initial international assistance after bilateral agreements with other states. Aspects of compulsory insurance of assets, of legislative documents which set standards in terms of quality of construction and materials used are very important [9].

Interdependencies, regardless of their type, can lead total or partial inability of different infrastructures from different sectors and may have direct effects on the population, economy and not least can have negative effects on the national security. In terms of infrastructure, there are dependence or interdependence relationships which should be analyzed in time. In the short term, after natural disasters, the first impact is on infrastructure in the geographical proximity and the repercussions are multiple: from lack of power supply or drinking water to isolation of population by destruction/ limitation of access roads and communication routes destruction. Each infrastructure affected in turn can produce domino effects with serious implications for the economy or safety.

As simulation, in order to determine the degree of vulnerability, equal shares to demographic, social, national indicators and interdependencies were considered. Setting the index of vulnerability to floods for a rural region, largely agricultural, with an aging population, where short term interdependencies affect the sectors of water supply, energy, communications and transport, we get a great value - 5.10 (figure 2) - compared to the same simulation in an area where the population is predominantly urban (figure 3), even though the population density is higher in the area. The situation changes in the event of a prolonged drought which may affect in a medium or long term, including energy production in nuclear plants.

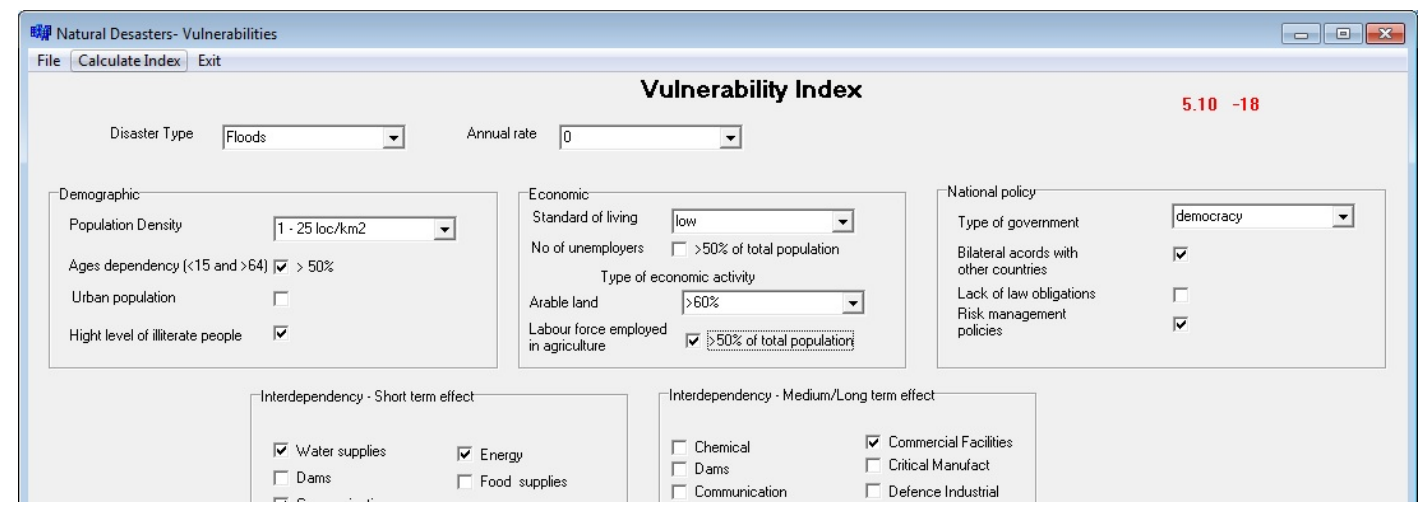

Figure 2. Index of vulnerability to flood for a largely agricultural area 


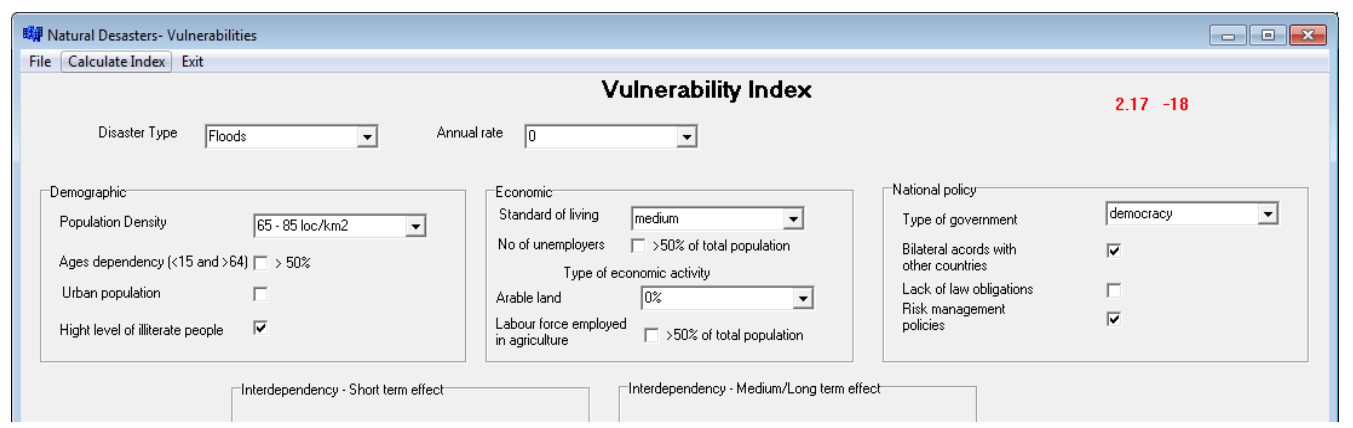

Figure 3. Index of vulnerability to flood for an urban area

\section{Conclusions}

Vulnerability estimation based on measurable factors in the economic, social or educational reasons are varied, while policy, physical and environmental indicators are more difficult to measure or estimate. The indicators that fall in estimating vulnerabilities may change slightly over time, but in terms of the vulnerability of population, this can undergo dramatic changes especially during conflicts or natural or human-made hazardous events.

Depending on the type of the natural disaster, the indicators falling in determining the vulnerability may have different shares, therefore, it is necessary to continue research by differentiated analysis, depending on the impact of each factor and implementing in a GIS environment which has tools that provide a meaningful analysis of interdependencies.

\section{References}

[1] Birkmann J., Indicators and criteria for measuring vulnerability: Theoretical bases and requirements, in Measuring Vulnerability to Natural Hazards: towards disaster resilient society, edited by Birkmann, United Nations University press, pp. 55-77, 2013.

[2] Flammini F., Critical Infrastructure Security: Assessment, Protection, Prevention, Detection, Response. Wit Press, Boston, 2012.

[3] Rinaldi S., Peerenboom J., Kelly T., Identifying, Understanding, and Analyzing Critical Infrastructure Interdependencies, IEEE Control Systems Magazine, IEEE, pp. 11-25, December 2001.

[4] UNDP/BCPR: A Global Report: Reducing Disaster Risk, a Challenge for Development, ISBN 92-1-126160-0, 2004, available http://www.undp.org/content/undp/en/home/ librarypage/crisis-prevention-and-recovery/reducing-disaster-risk--a-challenge-fordevelopment.html

[5] Birkmann J., Risk and vulnerability indicators at different scales: Applicability, usefulness and policy implications, Environmental Hazards 7, pp. 20-31, Elsevier 2007.

[6] Bucovetchi Olga Maria Cristina, Badea Dorel, Simion Cristina Petronela, Business Continuity Applied to Education, in the $12^{\text {th }}$ International Scientific Conference eLearning and Software for Education, Bucharest, April 21-22, 2016, vol. 1, p.409-414

[7] Schneiderbauer S., Ehrlich D., Social levels and hazard (in)dependence in determining vulnerability, in Measuring Vulnerability to Natural Hazards: towards disaster resilient society, edited by Birkmann, United Nations University press, pp. 78-102, 2013.

[8] Peduzzi P., Dao H., Herold C., Mouton F., Assessing global exposure and vulnerability towards natural hazards: the Disaster Risk Index, in Natural Hazards and Earth System Sciences, 9, pp. 1149-1159, 2009.

[9] Pederson, P., Dudenhoeffer, D., Hartley, S., Permann, M., Critical infrastructure interdependency modeling: a survey of U.S. and international research. Technical Report INL/EXT-06-11464. Idaho National Laboratory, 2006. 